\title{
The Relationship Between Personality Features and Academic Performance in Medical Students
}

\author{
Malekfarhad Malek ${ }^{1}$, Mahdieh Moinalghorabaei ${ }^{1,{ }^{*}}$, Mohammad Lesanpezeshki ${ }^{2}$ and Abolfazl \\ Mohammadi $^{1}$ \\ ${ }^{1}$ Department of Psychiatry, School of Medicine, Tehran University of Medical Sciences, Tehran, Iran \\ ${ }^{2}$ Department of Psychiatry, Columbia University, New York, United States \\ "Corresponding author: Department of Psychiatry, School of Medicine, Tehran University of Medical Sciences, Tehran, Iran. Tel: +98-9121777092, Fax: +98-2155419113, Email: \\ moin_drm@yahoo.co.uk
}

Received 2019 July 15; Revised 2019 October 07; Accepted 2019 October 11.

\begin{abstract}
Background: Investment in improving the quality of education can pave the way for sustained development. There are several studies, which have shown that personality features are important factors in predicting academic performance such as intelligence and cognitive ability. Mental disorders are one of the most severe complications of personality disorders, which influence academic performance, as well as students' quality of life. Therefore, early diagnosis and treatment of personality disorders can help prevent students' academic failure.

Objectives: This study can provide a better understanding of the prevalence of personality features and disorders among students. This may be of great value for providing mental health care for the students who demonstrate certain traits. Furthermore, this may be helpful for education policymakers to provide guidelines and update their student health monitoring process for the universities.

Methods: This cross-sectional study was conducted in 2015 at Tehran University of Medical Sciences, School of Medicine. We have used convenience sampling. A total of 107 questionnaires were administered to the students, and overall 96 valid questionnaires were collected from the participants. The association between personality features and academic performance in medical students was evaluated through Minnesota Multiphasic Personality Inventory (MMPI-2), which assesses personality features and psychopathology. Thus, the 370-item MMPI-2, as well as the academic performance questionnaire (including national university entrance exam rank, grade point average (GPA) of the first five terms, National Basic Science Exam Grade), was given to the students. Results: The results were statistically analyzed using Spearman's correlation and Independent sample $t$-test. Among the Clinical scales, the highest scores belonged to the following scales: Hypomania (\%24), depression (\%23), hysteria (\%20.8), masculinityfemininity (\%17.8), hypochondriasis (\%17.7), and social introversion (\%13.5), respectively. Concerning the relationship between each of these scale scores and academic performance, the scores of clinical scales of hypomania, hysteria, masculinity-femininity, hypochondriasis, and paranoia, had a significant relationship (all of the P values were $<0.05$ ) with academic performance. Moreover, the scores of validity scales of Infrequency and Lie had significant negative correlations (P values $<0.05)$ with academic performance.
\end{abstract}

Conclusions: The scores of Hypomania, Hysteria, Masculinity-Femininity, Hypochondriasis, and Paranoia scales correlated with students' academic performance.

Keywords: Academic Achievement, Academic Performance, Personality Features, Personality Traits, MMPI-2

\section{Background}

One of the most important factors in reaching sustained development is the ability to improve the quality of the educational system and the way every person with a different character could benefit the most from education (1). Having a high IQ alone does not guarantee a successful academic performance (2). In fact, many recent studies suggest that some personality traits could also help pre- dict the success rate. Personality is a way of thinking, feeling, and behaving found in an individual (3). Although most people have their own particular way of flexibility and adaptation in response to different stimulations, they still have a unique reaction to specific situations. Our character is not solid and it can change as time passes. We learn from our past experiences and propose different answers to different circumstances. Interestingly, we do not see this adaptability with people suffering from personality disor-

Copyright (c) 2019, Author(s). This is an open-access article distributed under the terms of the Creative Commons Attribution-NonCommercial 4.0 International License (http://creativecommons.org/licenses/by-nc/4.0/) which permits copy and redistribute the material just in noncommercial usages, provided the original work is properly cited. 
ders (4); they use the same reaction to different situations. Personality disorders are a pervasive, durable, and inflexible pattern, which result from inner experiences along with outer behaviors and lead to helplessness and frustration in the patient. In other words, diagnosis is made when the patient or the people whom they are in contact with, suffer from the patient's behavior. These disorders are chronic conditions, starting in adolescence or early adulthood and can last a lifetime. The disorder has an impact on every aspect of the patients' life, and it can result in decreased functioning, marital problems, and so on. Many studies have shown that people with these disorders have less life satisfaction, fragile interpersonal relationships, and lower job performances (5). To indicate the level of the burden caused by personality disorders, one study indicated that the burden caused by these disorders could be more than type 2 diabetes mellitus, HIV, and schizophrenia (6). Moreover, one of the most common consequences of personality disorders is psychiatric disorders. Therefore, early diagnosis of these personality traits/disorders can not only lead to the improvement of the level of success in education but also will prevent the development of a psychiatric disorder.

A personality disorder can drastically affect academic performance; however, the elevation in certain scales of personality features has also been shown to be associated with academic difficulties. In one study (7), it was indicated that higher scores in Psychopathic Deviate scale, Schizophrenia scale, Hypomania scale, and Social Introversion scale could negatively affect academic performance. In another study (8), it was demonstrated that having dysfunctional personality features, such as borderline, schizoid or antisocial characteristics, were associated with poor academic performance in medical students.

In this study, the researchers used Minnesota Multiphasic Personality Inventory (MMPI-2) to determine the association between personality traits and the academic performance of medical students. By performing this study, the prevalence of each personality trait could be determined, and by addressing them, one could prevent the critical effects on the academic performance of students. In other words, MMPI-2 is the most common tool for evaluating personality disorders and diagnosing psychopathologies in the United States, thus it has been translated into more than 20 languages and its external validity has been confirmed (9). This questionnaire has a high test-rest reliability range, from 0.67 to 0.92 for men and from 0.58 to 0.91 for women (10). The Persian version of MMPI-2 was validated in 1995 with the test-retest reliability ranging from 0.36 to 0.92 for females and from 0.57 to 0.87 for males (11) and has been utilized in a couple of studies, such as in a study with a sample of 1,418 participants aged 18 to 80 years old. The results were satisfactory regarding the reliability of the test (12).

\section{Methods}

This cross-sectional study was done at Tehran University of Medical Sciences, School of Medicine in 2015. We used convenience sampling. A total of 107 questionnaires were administered to the students, and a total of 96 valid questionnaires were collected from the participants. Eleven of the collected questionnaires were either filled incompletely or had multiple answers to the same questions included in the study, according to the MMPI-2 manual. The only inclusion criterion for this study was being a third-year medical student at that university. These questionnaires were not completed during an interview with a psychologist. In fact, they were self-administered and the instructions on how to complete the questionnaire were given to the students. These questionnaires were filled at the medical school campus, during the students' free time. Then we collected questionnaires blindly. All demographic data, such as gender, date of birth, marital status as well as educational and academic histories, including rank in the national university exams, score of the national basic science exam, and grade point average (GPA) of the last five semesters of medical school were collected and entered the SPSS statistical analysis software. We used independent sample $t$-test and Spearman's correlation to analyze the data.

The Ethics Committee of the Tehran University of Medical Sciences, School of Medicine, approved this study according to the Declaration of Helsinki. Participants were enrolled in the study voluntarily and were assured of the confidentiality of their personal information.

\section{Results}

Of all the 96 participants, 55 were female and 41 were male; they were all 21 years old. Mean T scores of Depression Scale were significantly higher in females compared to males $(\mathrm{P}<0.015)$. Also, mean $\mathrm{T}$ scores of MasculinityFemininity scale were significantly higher in males than females $(\mathrm{P}<0.003)$. Moreover, the mean $\mathrm{T}$ score of hypochondriasis was higher in females than males $(\mathrm{P}<$ 0.002). In other scales, there were no significant differences between males and females.

Based on the results presented in Table 1, the mean $\mathrm{T}$ scores of Social Introversion scale had a significant positive correlation with GPA of the last five terms of the students $(\mathrm{P}=0.049, \mathrm{r}=0.225)$. However, it did not have any correlation with other educational records. Mean T scores of Hypomania scale had a significant negative correlation with the score of the National Basic Sciences Exam ( $\mathrm{P}=0.041, \mathrm{r}$ 
$=0.228$ ); however, no correlations with other educational factors were seen.

\section{Discussion}

Table 2 indicates that the scale in which the students most frequently had high scores was the Hypomania scale, with $24 \%$ of participants having scored higher than 65 . In previous studies, it has been shown that this scale has a negative correlation with age (13); therefore, higher scores were found in younger subjects. The participants in this study were third-year medical students; thus the high prevalence of this scale could be attributed to their age. Table 1 shows that hypomania also had a significant negative correlation with the National Basic Science Exam score, as well as other studies (7); thus Hypomania had an unfavorable effect on the students' academic performance. It is important to note that individuals with high hypomania scores have lower impulse control and are more hyperactive and distractible, while they have more difficulties in concentrating on a specific task, such as studying.

According to the results presented in Table 2, the next common scale was the Depression scale with $22 \%$ of the participants showing a score of 65 and higher. The scores were significantly more common in females than males. However, Table 1 shows that it had no correlation with the students' academic performance, while a previous study (14) showed a negative impact on the academic performance of students. The difference of the results between these two studies could be a consequence of different versions of MMPI (70 questions versus 370 questions) or because the participants of the current study were still too young to encounter major life events, such as getting married or finding a job (13). According to Doherty and Nugent, by obtaining higher levels of education, the impact of each scale on academic performance of the student would be increased (15).

High scores in Hysteria and Hypochondriasis scales were demonstrated in $21 \%$ and $18 \%$ of the participants, respectively (Table 2). Although these were more common in females, based on the results presented in Table 1, they had no significant effect on their level of academic performance. However, they had a significant negative impact on the academic performance of the male subjects. The impact of high scores in Hypochondriasis scale on academic performance was also shown in a previous study (14). High scores in Masculinity-Femininity scale were observed in $18 \%$ of the subjects (Table 2 ), and according to the manual of MMPI-2, it was within the normal range. This scale has a significant positive correlation with academic performance (13).

According to the current study as well as past reports (16), social Introversion has a positive impact on the aca- demic performance; the main reason is that while extroverts are spending time socializing, introverts spend more time indoors, especially on studying. This could be attributed to the impulse control character of the scale. The more control on impulsivity, the higher the academic performance. Further analysis of the data indicates that this effect was solely for the female students, and it has no significant impact on male students. If one considers the results of the current study, clear differences could be observed between male and female characteristics in predicting academic performance. The gender differences were seen in differential effects of high scores in Hysteria, Hypochondriasis, and Social Introversion on academic performance. The observed gender differences in these scales could be explained by greater socio-cultural acceptability of Hysteria, Hypochondriasis, and Social Introversion for females in the Iranian society; thus they experience less social pressure for Hysteria and Hypochondriasis traits and even get rewards for Social Introversion; therefore, their performance would be influenced less than males and even become better in case of social introversion.

It is important to note that the findings that were related to Social introversion are a controversial matter, and there are different and contradictory results. A previous study (2) attributed this controversy to different contexts and settings of studies. Another research (17) ascribed this notion to different levels of education in these studies; it was believed that by reaching higher levels of education, the assignments will become more complicated and formal, and require a more introvert and concentrated character to perform them. The next scale was Paranoia; although it was not very prevalent (Table 2 ), it had a negative impact on the academic performance of the male subjects (Table 1). This finding is consistent with another study, which used EPQ to measure the effect of Psychoticism on the academic performance of students (18).

The other scales of personality, Psychopathic Deviation, and Schizophrenia were not prevalent at all (Table 2) and did not affect academic performance of the subjects of this study (Table 1). Nevertheless, this could be a result of the small sample size of this study, as in a previous study (7), both of these scales had a negative impact on the academic performance of the students. Psychasthenia was seen in $9 \%$ of the subjects (Table 2 ). It did not influence academic performance (Table 1 ), which could be because the third-year students had not reached higher levels of education and as mentioned previously, reaching higher levels of education in life can increase the chance that academic performance is affected by character (15). Additionally, there was a possibility that some aspects of this scale, such as being accurate and arranged, perfectionist, and having conscientiousness could have a positive impact on their academic performance. As some other studies, which 


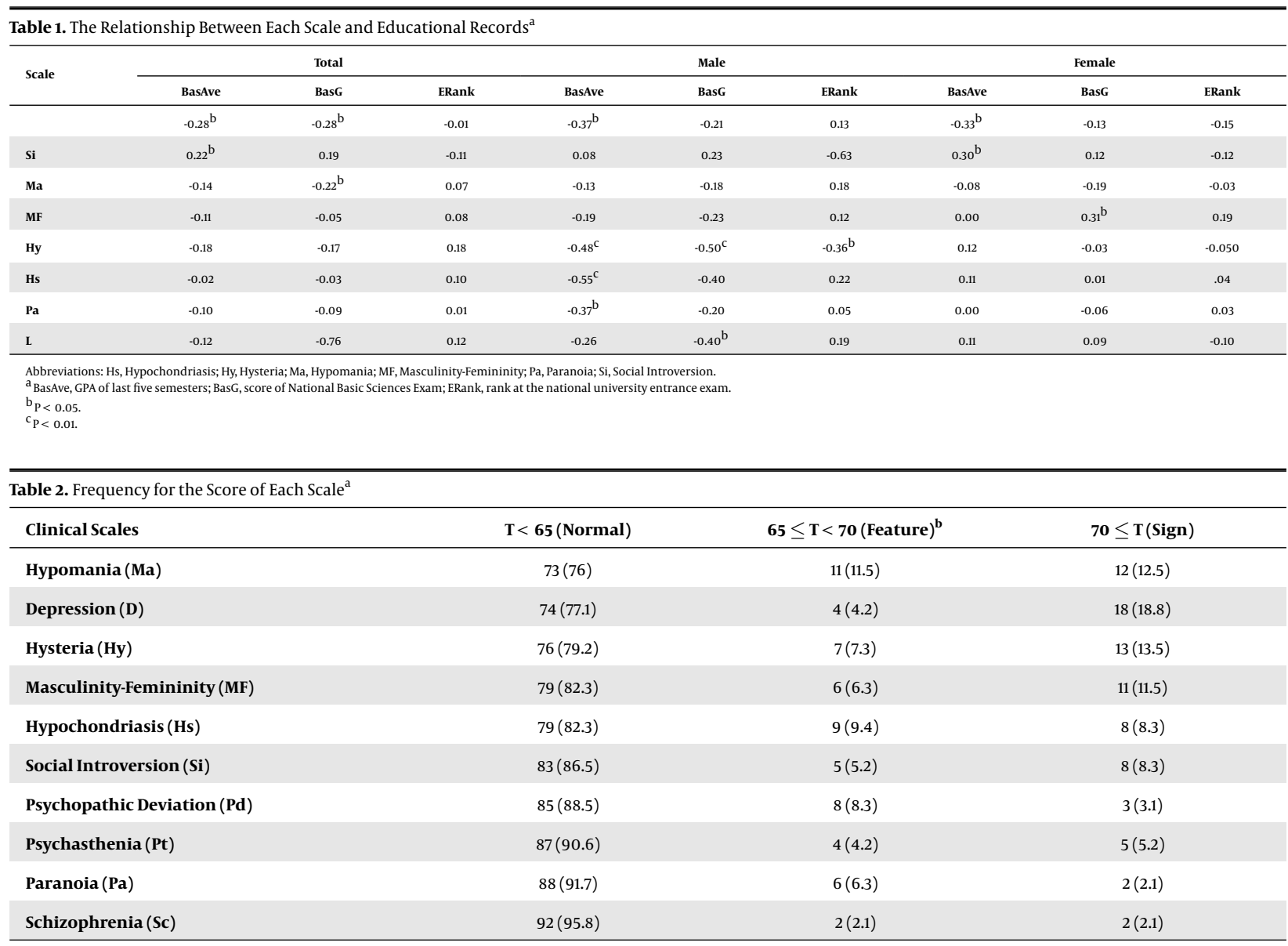

${ }^{\mathrm{a}}$ Values are expressed as No. (\%)

${ }^{\mathrm{b}}$ Feature can be interpreted as a personality trait, not like sign, which is more severe and pervasive.

used NEO and EPQ questionnaires, proposed that conscientiousness has some positive effects on the academic performance, thus a hypothesis could be suggested, in which Psychasthenia is comprised of two sub-categories: Neuroticism and Conscientiousness. The former has an adverse effect on academic performance, and the latter has a positive one. This theory could be assessed in another study using both NEO and MMPI-2 questionnaires.

The last three scales are credit scales: Infrequency (exaggeration of psychopathologic symptoms), Defensiveness (unintended denial of psychopathologic symptoms), and Lie (intentional false responses). They all have negative correlations with academic performance, with the Infrequency scale having the highest correlation (Table 1). Another previous research (7) suggested that infrequency could show the level of distractibility of the subjects.

\subsection{Limitations of the Study and Suggestions}

It has been suggested that there is a difference in personality traits among people with low and high IQ (19).
However, the current research did not perform any assessments of the intelligence due to time restrictions and limited availability of medical students. However, the researchers concluded that the rank of the national university entrance exam as a proxy measure could be continued, since there are some studies indicating a significant correlation between the level of intelligence and high school academic achievement (20-22). The sample population for the current study was selected from the top-ranked medical school in the country. Therefore, the variance of the IQ within the sample population may be minimal; hence the need for performing additional IQ assessments seems unnecessary.

Also, the high number of questions of this questionnaire could be a potential limit to the study; however, in the current study, only 11 subjects did not complete the questionnaire; thus it did not have an important effect on the final results of the study. The other limitation of this study was that it was performed only on students who attended the class, and it could potentially have some ad- 
verse effects on the final results by under-evaluating some of the undesirable personality traits. Also, those who are not determined enough to attend the classes regularly might show different academic performances than those who attend. To resolve this problem, the researchers tried to make sure that everybody was present in that class and the questionnaire was distributed at the busiest time of the classes. Another limitation was that the subjects studied were from a specific year in one medical school. As some studies suggest, age and the level of education have several impacts on the outcome of the results (15); thus we suggest continuing this study on participants from different levels of education and more culturally diverse populations to address the controversial results, especially the Masculinity-Femininity scale.

\section{Footnotes}

Authors' Contribution: Study concept and design was done by Malekfarhad Malek and Mahdieh Moinalghorabaei. Acquisition of data was done by Malekfarhad Malek. Analysis and interpretation of data was done by Mohammad Lesanpezeshki, Malekfarhad Malek, Mahdieh Moinalghorabaei, and Abolfazl Mohammadi. Drafting of the manuscript was done by Mohammad Lesanpezeshki and Malekfarhad Malek. Critical revision of the manuscript for important intellectual content was done by Malekfarhad Malek and Mahdieh Moinalghorabaei. Statistical analysis was done by Mohammad Lesanpezeshki and Malekfarhad Malek. Administrative, technical, and material support was done by Mahdieh Moinalghorabaei and Abolfazl Mohammadi. Study supervision was done by Mahdieh Moinalghorabaei and Abolfazl Mohammadi.

Clinical Trial Registration Code: This study is not a clinical trial.

Conflict of Interests: The authors declare that they have no conflict of interests.

Ethical Approval: This study has been approved by the Ethics Committee of Faculty of Medicine at Tehran University of Medical Sciences but unfortunately there is no code available now despite trying to obtain it, so we got a letter that confirms the ethical approval by the Vice-Chancellor of Research of the Faculty and uploaded it as cover letter.

Funding/Support: This study was supported by a Grant to the Doctoral Thesis from Tehran University of Medical Sciences.

Informed Consent: Participants were enrolled in the study voluntarily and were assured of the confidentiality of their personal information.

\section{References}

1. Hakimi S, Hejazi E, Gholamali Lavasani M. The relationships between personality traits and students' academic achievement. Procedia Soc Behav Sci. 2011;29:836-45. doi:10.1016/j.sbspro.2011.11.312.

2. Chamorro-Premuzic T, Furnham A. Personality predicts academic performance: Evidence from two longitudinal university samples. $J$ Res Pers. 2003;37(4):319-38. doi:10.1016/s0092-6566(02)00578-0.

3. Kazdin AE. Encyclopedia of psychology. 1st ed. Washington, DC: American Psychological Association; 2000. doi: 10.1037/10516-000.

4. Comer R. Abnormal psychology. 4th ed. New York: Worth Publishers; 2001. $611 \mathrm{p}$.

5. Lim D, Sanderson K, Andrews G. Lost productivity among fulltime workers with mental disorders. J Ment Health Policy Econ. 2000;3(3):139-46. doi: 10.1002/mhp.93. [PubMed: 11967449].

6. Soeteman DI, Verheul R, Busschbach JJ. The burden of disease in personality disorders: Diagnosis-specific quality of life. $J$ Pers Disord. 2008;22(3):259-68. doi: 10.1521/pedi.2008.22.3.259. [PubMed: 18540798].

7. King AR, Bailly MD. MMPI-2 Predictors of academic performance.JPsychoeduc Assess. 2016;20(3):258-67. doi: 10.1177/073428290202000303.

8. Knights JA, Kennedy BJ. Medical school selection: Impact of dysfunctional tendencies on academic performance. Med Educ. 2007;41(4):362-8. doi: 10.1111/j.1365-2929.2007.02707.x. [PubMed: 17430281].

9. Butcher JN, Atlis MM, Hahn J, Hilsenroth MJ, DL S. Comprehensive handbook of psychological assessment. Hoboken, New Jersey: Wiley Online Library; 2004

10. Butcher JN, Dahlstrom WG, Graham JR, Tellegen A, Kaemmer B. MMPI2: Manual and administration scoring. Minneapolis: University of Minnesota Press; 1989.

11. Mootabi FSA. [Preparation and standardization of the MMPI-2 scale in Tehran]. Tehran; 1995.

12. Dehghani M, Ashori A, Habibi Askarabad M, Khatibi M. Standardization and psychometric properties of Minnesota Multiphasic Personality Inventory (MMPI-2). J Psychol. 2010;14(3).

13. Graham JR. MMPI-2: Assessing personality and psychopathology. 5th ed. UK: Oxford University Press; 2011. 688 p.

14. Samouei R, Fooladvand M, Janghorban S, Khorvash F. Predicting the educational performance of Isfahan University students of medical sciences based on their behaviour profile, mental health and demographic characteristic. J Educ Health Promot. 2015;4:44. doi: 10.4103/2277-9531.157230. [PubMed: 26097858]. [PubMed Central: PMC4456873].

15. Doherty EM, Nugent E. Personality factors and medical training: A review of the literature. Med Educ. 2011;45(2):132-40. doi: 10.1111/j.13652923.2010.03760.x. [PubMed: 21208259].

16. Rolfhus EL, Ackerman PL. Assessing individual differences in knowledge: Knowledge, intelligence, and related traits. J Educ Psychol. 1999;91(3):511-26. doi: 10.1037/0022-0663.91.3.511.

17. Anthony WS. The development of extraversion, of ability, and of the relation between them. Br J Educ Psychol. 1973;43(3):223-7. doi: 10.1111/j.2044-8279.1973.tb02261.x. [PubMed: 4759966].

18. Ciorbea I, Pasarica F. The Study of the relationship between personality and academic performance. Procedia Soc Behav Sci. 2013;78:400-4. doi: 10.1016/j.sbspro.2013.04.319.

19. Waiyavutti C, Johnson W, Deary IJ. Do personality scale items function differently in people with high and low IQ? Psychol Assess. 2012;24(3):545-55. doi: 10.1037/a0026266. [PubMed: 22082036].

20. Jensen AR. The $g$ factor: The science of mental ability. Psicothema. 1999;11(2):445-6.

21. Frey MC, Detterman DK. Scholastic Assessment or g? The relationship between the Scholastic Assessment Test and general cognitive ability. Psychol Sci. 2004;15(6):373-8. doi: 10.1111/j.0956-7976.2004.00687.x. [PubMed: 15147489].

22. Colom R, Flores-Mendoza CE. Intelligence predicts scholastic achievement irrespective of SES factors: Evidence from Brazil. Intelligence. 2007;35(3):243-51. doi:10.1016/j.intell.2006.07.008. 